\title{
Considerations Regarding Calculation Cost in the Machine Building Industry
}

\author{
Gabriela Marian, Mecanica Ceahlău SA Piatra Neamț
}

\begin{abstract}
Summary
The paper structures the advantages and the disadvantages of the determination method of the standard cost. The need of the enterprises to operate with production scientifically established and verifiable costs is a recognized fact by the practice and standard computer technology cost although meets the technology requirements, keeps the deficiencies traditional techniques.
\end{abstract}

\section{Keywords}

Diagnosis, standard cost, direct costs, fixed overhead charges, variable overhead charges.

JEL Code: M41

\section{Structuring the process of financial analysis}

The interpretation of the operations of an enterprise is done mainly through the analysis of economic and financial indicators in the financial statements Balance and Profit and Loss Account, summary account documents which give a fair, clear and complex image of the patrimony of the financial position and on performance of asset unit. The indicators are best understood when are approached as a system of correlations, sensitive to the management decisions on which occurs the evolution of the specific vectors of value creation.

The economic and financial diagnosis involves the research of an economic phenomenon or process which involves correlative the emphasize of both the esigned highlight efforts through the consumption of material, human and financial resources, and of the effects that are circumscribed to the results as social useful values. Since socio-human activity has double aspects of consuming resources and effects generating, this makes that the economic analysis to exceed the scope of economic activity, targeting the efficiency of resources consuming in all areas (including social, technical, administrative, etc.).

The structure of the financial analysis process into economic and financial indicators will consider the following very important for accuracy results:

- clear definition of the analysed problem and the adopted perspective: each type of simple or complex analysis must be preceded by a clear definition of the analysed problem and a choice of working perspective, which will naturally lead to a selection of indicators for analysis;

- $\quad$ using an optimal combination of primary and secondary indicators and of the analytical instruments: is better to establish which are the suitable indicators of a problem and which secondary indicators may provide additional information;

- identify the key vectors which creates the value that affects business performance: testing the sensitivity of selected key indicators at various developments of the vectors performance and including the critics vectors of value as part of the mix of measures chosen to assess the performance of the analysed business; 
- finding of any comparison standards and of any additional data for analysis: performance analysis is accomplished in the context of comparative data about the industry or key competitors;

- creating a historical trend and a forecast of economic and financial performance: it must be judjed in a temporal context to the nature of business and industry including the cycle, seasonality, growth and decline.

The trend analysis becomes extremely important for predicting the future conditions in the context of predictable events;

- using historical performance as indicators of future expectations: past performance trends must be tested compared to expectations of future economic conditions, both internal and foreign affairs in the general business, competition and macroeconomic situation;

- the recognition and the identification of problems and obstacles to the optimal performance: the economic and financial performance analysis in the wide sense should be viewed in the context of the business system; the policies and the strategies of the investment, operation and financing segment must be mutually supportive.

The economic and financial indicators are not absolute criterions, they serve only to reflect the financial conditions and the operational performance for certain periods of time compared with similar businesses. To become useful an indicator must be understood both as meaning and as a limitation, each indicator is useful only in connection with a point of view beeing as a hypothesis and with a pursued objectives. Most times, the analytical procedures applied by analysts involves the use of financial indicators relevant for understanding of the latest events and of the financial condition of the business and the tackle of financial statements of the user's perspective.

The analysts are doing an estimation regarding a financial indicator by analyzing data from past years, of the evolution trends in branch of the budget estimations and non-financial information.

The shortcomings of economic and financial analysis are related to limitations of traditional accounting principles, the managers and the analysts will adopt an economic perspective based on cash flows, for substantiation and taking of decisions, which will cause long term performance based on accounting information.

\section{Cost calculation in the machine building industry}

A permanent account challenge is related to fair allocation of a part of cost which is accumulated in the management accounting over the sold goods.

The need of enterprises to operate with scientific production determined and controled costs is a reality recognized by the practice, and the calculation techniques based on established standards in advance with the view of stocks calculation that comply to the requirements of the technological processes and in the organizational structures in machine building enterprises. The standard cost takes into account the normal levels of materials and supplies, labor, efficiency and established production capacity in scientific manner based both on data from previous periods and on anticipated related elements of business conditions.

Using the standard cost method in the machine building industry should not be considered independently, since it overlaps to the orders method, so that the organization calculation process to allow the costs estimation and the establishment of the causes of the deviations from pre-scientific standards.

The basic concept of the standard technique cost is to establish in advance the cost of conversion of inventories which includes directly costs related to produced units (materials, direct labor) and systematic allocation of fixed and variable production overheads charges. Fixed overhead charges are those indirect costs of production that remain relatively constant 
regardless the volume production. Variable overhead charges of production are those indirect costs of production that vary directly or nearly directly with production volume.

The allocation of fixed overheads charges on the costs production is based on normal capacity of production and the distribution of the current orders is based on direct labor. Normal production capacity is expected to be achieved in average over certain periods or seasons. Since the restructuring of the machine building industry have limited the activity in spaces under the design capacity, the current production level is considered that approximates the normal capacity.

This technique is limited by the provisional calculated standard costs that are considered the real or normal production costs and it is the base for saling prices. The more or less differences between actual and standard costs are considered deviations from the normal conditions of manufacture and it affects directly the company's financial results.

The standard costs technique has the advantage to enable the machine building enterprises that have organized the collection costs by the orders method at the projected costs determination for fast assessment of obtained production forecast, but the disadvantage that preserves the deficiencies of traditional method: the big workload to achieve analytical filing system of changes of regulations and of deviation by making separate papers for all identified quantitative deviations on products and places of expenses.

Most of the calculating techniques cost allow variations in the extent they are predictable, but the significant changes affect costs periodically allocated in the income distributed periodically.

\section{Bibliography}

1. Călin, O (coordinating); Manolescu, M and collaborators „,Management accounting”, Economic Publishing, Bucharest 2000

2. Erich A. Helfert: ,,Financial analysis techniques”, BMT Publishing, Bucharest 2003

3. IASCF 2007 : „International Accounting Standard 2 Inventories”

4. Işvănescu, A. coordinating: "Economic and financial analysis" ,Publishing ASE, Bucharest 2004 